\title{
BMJ Open Impact of rural Family Physician programme on maternal and child health indicators in Iran: an interrupted time series analysis
}

\author{
Hossein Jabbari Beyrami, ${ }^{1}$ Leila Doshmangir, ${ }^{2,3}$ Ayat Ahmadi, ${ }^{4}$ \\ Mohammad Asghari Jafarabadi, ${ }^{5,6}$ Esmaeil Khedmati Morasae, ${ }^{7}$ \\ Vladimir S Gordeev ${ }^{8}$
}

To cite: Jabbari Beyrami H, Doshmangir L, Ahmadi A, et al. Impact of rural Family Physician programme on maternal and child health indicators in Iran: an interrupted time series analysis. BMJ Open 2018;9:e021761. doi:10.1136/ bmjopen-2018-021761

- Prepublication history for this paper is available online. To view these files, please visit the journal online (http://dx.doi. org/10.1136/bmjopen-2018021761).

Received 29 January 2018 Revised 29 0ctober 2018 Accepted 28 November 2018

Check for updates

(C) Author(s) (or their employer(s)) 2018. Re-use permitted under CC BY-NC. No commercial re-use. See rights and permissions. Published by BMJ.

For numbered affiliations see end of article.

Correspondence to

Dr Leila Doshmangir;

Doshmangirl@tbzmed.ac.ir

\section{ABSTRACT}

Objectives The establishment of the Family Physician (FP) programme in the rural areas of Iran in 2005 has made health services accessible and affordable. This paper aims to assess the overall trends of maternal and child health (MCH) indicators in a 20-year period and possible effects of the FP programme (intervention) on these indicators in Iran.

Design and setting An interrupted time series analysis was conducted on 20 annual MCH-related data points from 1994 to 2013. The intervention time was at the 12 th data point in 2005.

Outcomes $\mathrm{MCH}$ indicators were grouped into three categories: structure (mother's age, education, occupation and gravidity), process (number of antenatal care visits (ACVs), laboratory tests, ultrasounds and natural vaginal deliveries (NVDs)) and outcomes (maternal mortality ratio (MMR), neonatal mortality rate (NMR), birth weight (BW), history of abortion and/or stillbirth, and haemoglobin level (Hb)). Results The adjusted slope of the ACV trend decreased sharply after the intervention $(b=-0.36, p<0.01)$, whereas it increased for the frequency of ultrasounds $(b=0.2, p<0.01)$ and did not change for number of laboratory tests $(b=-0.09$, $p=0.95)$. The intensification of the descending slope observed for NVD ( $b=-1.91, p=0.03$ ) disappeared after the adjustment for structural confounders $(b=1.33, p=0.26)$. There was no significant slope change for MMR $(b=1.12, p=0.28)$ and $\operatorname{NMR}(b=0.67, p=0.07)$ after the intervention. The slope for the history of abortion trend was constant before and after the intervention, but it considerably intensified for the history of stillbirths after the intervention $(b=1.72, p<0.01)$. The decreasing trend of $B W$ turned into a constant mode after the intervention $(b=33.2, p<0.01)$, but no change was observed for $\mathrm{Hb}(\mathrm{b}=-0.02, \mathrm{p}=0.78)$.

Conclusion Although the FP programme had a positive effect on the process and proximal outcome indicators (BW), no dramatic effect on mortality outcome indicators was distinguished. It shows that there should be determinants or mediators of mortality outcomes in this setting, other than accessibility and affordability of MCH services.

\section{INTRODUCTION}

Following the Alma-Ata Declaration of 1978, the Islamic Republic of Iran (Iran) began to expand its primary healthcare (PHC)
Strengths and limitations of this study

- The time frame of the study (1994-2013) gives a comprehensive picture of the effects of policy intervention (the Family Physician programme) on maternal and child health indicators through a natural experiment design.

- Due to almost complete coverage of the rural areas by the national health network and the random sampling method used in this study, the risk of selection bias is very low.

- Our study population can be considered to be the country's rural area representative, as there were no significant dissimilarities in the participants' demographic and health indicators with the country reported averages.

- No comparison group was available since the Family Physician programme was implemented countrywide. Therefore, we could not discriminate the effect of time varying confounders, such as socioeconomic changes, from the main effect of the intervention. In addition, the ecological fallacy in the interpretation of results of aggregate indicators (maternal mortality ratio, neonatal mortality rate) is not impossible.

network. ${ }^{1-4}$ This publicly funded and extensive PHC network offered health houses staffed by trained health workers, known as behvarz in Persian, ${ }^{56}$ to rural residents. Behvarzes were the main service providers and were responsible for provision of antenatal and postnatal maternal care for uncomplicated pregnancies, as well as other PHC components. ${ }^{7-9}$ A health house was a peripheral unit of the PHC network that served about 1500 inhabitants in a rural area. ${ }^{10}$ Every four to seven health houses were linked to a health centre, led by one family physician, located in the closest biggest village. As such, the health centre was providing a service to approximately 7000-10 000 people. ${ }^{11}$ This health centre 
was responsible for the provision of a defined health package for a population in their associated catchment rural area, which included outpatient visits, medical laboratory tests, medication, midwifery and other services. Overall, this well-organised PHC network substantially contributed towards reduction in infant, maternal and newborn mortality rates during the last two decades of the 20th century. ${ }^{12-15}$

Since 2000, the promotion of maternal and child health $(\mathrm{MCH})$ care through the provision of related services and recording of MCH-related indicators became a top priority for the Iranian PHC network. ${ }^{16}{ }^{17}$ As of 2005, with the start of the second PHC-based reform known as Family Physician (FP) programme, ${ }^{18}$ the way each health centre (now referred to as FP team) functions within the PHC network has changed. The FP team structure was expanded to include additional staff, such as a general physician, midwives and a pharmaceutical technician. ${ }^{17}{ }^{19-21}$ Now, one family doctor was settled in each village, so the size of the rural population serviced by the FP team was limited to $3000-4000$ people.

A new insurance plan (Rural Health Insurance) was also scaled up to cover the whole Iranian rural population. The previously limited duration of the service provided by the FP team (from 08:00 to 14:00) also changed to become a round-the-clock service, with triple the number of physicians available in the rural areas. ${ }^{3}$ In the new settings, the family physicians were now team coordinators and service providers. There was also a significant increase in the salary of general physicians involved in the FP programme. The FP programme also considerably improved accessibility and affordability of medical and health services, which among others included special antenatal and postnatal care, laboratory tests (including measurement of haemoglobin (Hb) levels to monitor iron supplementation plan) and routine ultrasounds to detect fetus abnormality. ${ }^{1920}$ The FP teams also started providing maternity care for all women in rural areas. ${ }^{22}$

Like Iran, many countries (eg, Pakistan, India, Rwanda, China, African and Latin American countries) are making serious sector reforms ${ }^{23-30}$ to provide effective and highquality MCH services. The main aim of these reforms is to decrease maternal, neonatal and infant mortalities and achieve Sustainable Development Goals. ${ }^{31}$ However, there is no extensive evidence as to whether such health reforms have led to improvements in health systems performance and indicators. ${ }^{32}$ Iranian health sector reforms are no exception to this. After a decade since the FP reform implementation in the rural areas, one could expect considerable changes to be observed in $\mathrm{MCH}$ indicators in Iran. However, any possible changes were not yet extensively studied, evaluated and/or reported. Therefore, the main goal of this study was to investigate the impact of Iran's FP reform on selected MCH indicators, using the data from 1994 to 2013 for the northwest Iranian province East Azerbaijan.

\section{METHODS}

For the evaluation of population-level interventions based on population indicators rather than individual measures, an interrupted time series analysis (ITSA) is recommended. ITSA is also a desired method for the evaluation of health policies, particularly when their targeted indicators have been repeatedly measured in a defined population over a time period. ${ }^{23}$ For our analyses, we developed ITSA regression models following the steps introduced by Bernal et al, ${ }^{23}$ using Stata V.13.1 (StataCorp, College Station, Texas, USA).

\section{Step 1: study design and its appropriateness}

\section{Population and data}

The data were collected in the rural area of East Azerbaijan, a northeast province of Iran. The province covers an area of approximately $47830 \mathrm{~km}^{2}$ and constitutes roughly $5 \%$ of the country's population (2013). In 2013, $26 \%$ of the population resided in rural areas, a decrease from $35 \%$ in 1994 . The overall population growth rate in the rural area decreased from $1.42 \%$ (in 1994) to $1.31 \%$ in 2013. The total fertility ratio decreased from 2.88 in 1994 to 2.11 in 2013.

Virtually all pregnancies in the rural areas of Iran are covered by health houses ${ }^{3}$ and related information is recorded in households' health files from mid-1980s. As a result, the longitudinal data are available on the care delivered during pregnancy and childbirth, and development until school age, for more than three decades and for all women.

For our study, we used these rural health houses data at the individual level. The sample frame consisted of a list of all pregnancies in different health houses in a specific year in associated geographical area. Since health houses have almost $100 \%$ coverage for their reference population in rural areas, the sampling was done in a simple random selection way. Given the average number of annual live births (roughly 2000 in 1994-2013), we randomly selected $10 \%$ of all pregnancy cases in a given year, which were then retrospectively followed up until the end of the pregnancy. This resulted in approximately 200 cases a year and a total of 4096 cases of pregnancies from 1994 to 2013.

\section{Intervention and comparison}

The multicomponent intervention, called the FP programme, was considered an intervention. This intervention was composed of a package of medical, maternal and childcare services. It also aimed to make healthcare services affordable through a new insurance plan. The programme was launched in 2005. The intervention time in the present study, therefore, ranged from 2005 to 2013. The comparison time, in contrast, was the time prior to the implementation of the FP programme (ie, 1994-2004).

\section{Outcome}

The Donabedian model was used for categorisation of $\mathrm{MCH}$ indicators. This model emphasises the importance 
of structure, process and outcome $e^{33}$ in healthcare services assessments. The mother's age, level of education, occupation and gravidity were considered as structure variables in this study. They were used as confounders and their effects were controlled in all statistical models. The number of antenatal care visits (ACVs), history and frequency of ultrasounds, laboratory tests and type of delivery were considered as process indicators in this study. Maternal mortality rate (MMR), neonatal mortality rate (NMR), history of abortion and/or stillbirths were also considered as outcome indicators. The values for MMR and NMR were obtained from the annual national reports of health indicators for the study population. MMR, NMR, abortion and stillbirth ratios indicators were defined following WHO guidelines. ${ }^{34}$ Other outcome indicators included birth weight (BW), which was recorded regardless of the gestational age, and the value of $\mathrm{Hb}$ in the first test during the 3-month pregnancy period.

\section{Step 2: the impact model}

ITSA regression models were used to assess the causal links between the programme as an intervention and the outcomes of interest. To conduct the ITSA, the following three variables were added into the model: a time variable (trend), showing the time elapsed from the beginning of the study time frame (1994) until the end of the study period (2013); a dummy variable (programme) representing the time before and after the intervention; and an interaction term which represented the joint effect of the time trend of indicators and the implementation of the intervention.

\section{Step 3: descriptive analysis}

Descriptive analyses were illustrated as means $( \pm \mathrm{SD})$ for numeric variables and frequencies for categorical variables. The descriptive time trend line charts were used to present the process and outcome indicators over the time. The scatter plots were used to show the changes of process and outcome indicators over the study time points (years).

\section{Step 4: regression analysis}

We applied segmented regression models, where each segmented line was fitted through ordinary least squares. ${ }^{34}$ The following model was used to show the relationship between the variables:

$$
\begin{aligned}
y_{t}= & a_{t}+b_{1} I_{t}+b_{2} X I_{t}+b_{4} e d u_{t^{+}} \\
& b_{5} \text { age }_{t}+b_{6} j o b_{t}+b_{7} \text { no.pregnancyt }+e_{t}
\end{aligned}
$$

where $Y_{t}$ is the outcome variable in time $t$ and $I$ is the indicator of the elapsed time. Moreover, $X_{t}$ is a dummy variable that denotes the 'Before the programme' (coded as 0 ) and 'After the programme' (coded as 1) periods. The interaction variable $\left(X I_{t}\right)$ shows the changes in the slope of response variable time trend during the study period, by considering the intervention time point. $a_{t}$ is the baseline level of the outcome $(Y)$ when all independent variables are zero, $b_{1}$ is the unique effect of a time unit increase in pre-intervention time, $b_{2}$ is the mean change in the outcome following the programme if time remains constant and $b_{3}$ is the joint effect of time and the FP programme that represents the slope change following the intervention. The model was adjusted for potential confounders including age, mother's education level and occupation and gravidity. To account for autocorrelation, a random error $e_{t}$ was added to the model.

\section{Step 5: addressing methodological issues}

Since data for outcome and process were reported annually, seasonality was not indicated in the analysis. We assumed no other regular fluctuation or long-term trend over the study time period. A time lag of 1 year was used for mortality outcomes (MMR and NMR) to adjust for the time of actual change and the time when intervention was received by participants. Since we did not use a concurrent control group, unmeasured time-varying confounders, such as socioeconomic change during the study period, might distort the results. Nonetheless, we assumed no time-varying confounders other than those that we adjusted for in the model. We also assumed no overdispersion in the data. The Durbin-Watson transformed statistic was used as an indicator for exploring positive or negative first-order autocorrelation.

\section{Patient and public involvement}

No patients or members of the public were involved in this study.

\section{RESULTS}

Structural indicators of education level, occupation and the age of a pregnant women had changed from $39.3 \%$ $(\mathrm{n}=92), 82.1 \%(\mathrm{n}=234)$ and $23.63 \pm 4.73$ years $(\mathrm{n}=235)$ in 1994 to $58.60 \%(\mathrm{n}=113), 68.1 \%(\mathrm{n}=191)$ and $26.44 \pm 6.43$ years $(n=193)$ in 2013 , respectively. The gravidity for each woman decreased from $2.15 \pm 1.70$ to $1.5 \pm 1.02$ in the same years as well. Table 1 shows the changes in structure, process and outcome indicators before and after the FP implementation.

In terms of process indicators, the ratio of having at least one ultrasound during pregnancy had increased from $15.7 \%(\mathrm{n}=37)$ in 1994 to $100 \%(\mathrm{n}=185)$ in 2013. In contrast, the mean $( \pm \mathrm{SD})$ number of ACV $(9.13 \pm 3.67$, $\mathrm{n}=232)$, the first measured $\mathrm{Hb}(13.22 \pm 1.08, \mathrm{n}=139)$ and the ratio of normal deliveries $(84.6 \%, \mathrm{n}=198)$ had decreased to $6.43 \pm 1.80(\mathrm{n}=187), 12.83 \pm 0.99(\mathrm{n}=187)$ and $55.6 \%(\mathrm{n}=105)$, respectively. In addition, the number of routine laboratory tests and the frequency of ultrasounds for each woman had increased from $25 \%$ and $0.14 \pm 0.37$ in 1994 to $99.5 \%$ and $2.47 \pm 1.06$ in 2013 , respectively.

In terms of outcome indicators, MMR, NMR and mean of BW decreased from 32.51 (deaths per 100000 live births), 19.8 (deaths per 1000 live births) and $3429.70 \pm 495.33$ $\mathrm{g}$ in 1994 to 21.09 (per 100000 live births), 6.32 (per 1000 live births) and $3207.88 \pm 458.88 \mathrm{~g}$ in 2013 , respectively. In contrast, the proportion of the history of abortion and stillbirth increased from $2.8 \%(\mathrm{n}=2)$ and $1.4 \%$ 


\begin{tabular}{|c|c|c|c|c|}
\hline $\begin{array}{l}\text { Indicator category } \\
\text { (Donabedian model) }\end{array}$ & Indicator & $\begin{array}{l}\text { Before intervention } \\
\text { 1993-2004 }\end{array}$ & $\begin{array}{l}\text { After intervention } \\
\text { 2005-2013 }\end{array}$ & $P$ value \\
\hline \multirow[t]{4}{*}{ Structure indicators } & Mother age (mean $\pm S D)$ & $24.97 \pm 1.38$ & $25.77 \pm 0.69$ & $<0.001$ \\
\hline & Mother literacy (n, \%) & $916(39.30)$ & $695(41.3)$ & 0.216 \\
\hline & Mother job (housewife per cent) (n, \%) & $1963(82.30)$ & $1235(73.05)$ & $<0.001$ \\
\hline & No of gravities for each mother (mean \pm SD) & $2.39 \pm 0.35$ & $1.65 \pm 0.32$ & 0.691 \\
\hline \multirow[t]{5}{*}{ Process indicators } & No of ACV for each mother (mean \pm SD) & $9.02 \pm 0.30$ & $7.77 \pm 1.22$ & 0.114 \\
\hline & $\begin{array}{l}\text { Performing routine laboratory tests per cent (n, } \\
\%)\end{array}$ & $1086(79.4)$ & $1581(93.4)$ & $<0.001$ \\
\hline & Performing ultrasound per cent (n (\%)) & $668(29.10)$ & $1511(90.50)$ & $<0.001$ \\
\hline & No of ultrasound for each mother (mean \pm SD) & $0.30 \pm 0.13$ & $1.77 \pm 0.71$ & 0.116 \\
\hline & Delivery type (normal delivery) (n (\%)) & $1905(80.80)$ & $893(53.70)$ & 0.006 \\
\hline \multirow[t]{6}{*}{ Outcome indicators } & Maternal mortality rate $(\operatorname{mean} \pm \mathrm{SD})$ & $28.91 \pm 5.30$ & $18.94 \pm 4.77$ & 0.252 \\
\hline & Neonatal mortality rate $($ mean $\pm S D)$ & $18.23 \pm 3.01$ & $9.11 \pm 2.41$ & 0.274 \\
\hline & Abortions (n (\%)) & $212(9.7)$ & $296(24.8)$ & $<0.001$ \\
\hline & Stillbirths (n (\%)) & $64(3.00)$ & $53(5.2)$ & 0.002 \\
\hline & Birth weight $(\mathrm{g})($ mean $\pm \mathrm{SD})$ & $3313 \pm 81.19$ & $3173 \pm 26.28$ & 0.506 \\
\hline & Haemoglobin $($ mean $\pm S D)$ & $13.01 \pm .21$ & $12.86 \pm .25$ & 0.559 \\
\hline
\end{tabular}

$P$ value is significant at level of $\leq 0.05$.

$\mathrm{ACV}$, antenatal care visit.

$(\mathrm{n}=3)$ in 1993 to $14.5 \%(\mathrm{n}=39)$ and $8.6 \%(\mathrm{n}=7)$ in 2013 , respectively.

Figures 1 and 2 show the changes in process and outcome indicators. Figures 3 and 4 represent scatter plots of values of process and outcome indicators over the study time points.
Table 2 shows the results of ITSA (non-adjusted and adjusted for structure variables: mother's education, occupation, age and gravidity) on selected indicators. For each specified response indicator, if the intervention effect' is significant, it shows that the average values of the indicator before and after the intervention times (2005)

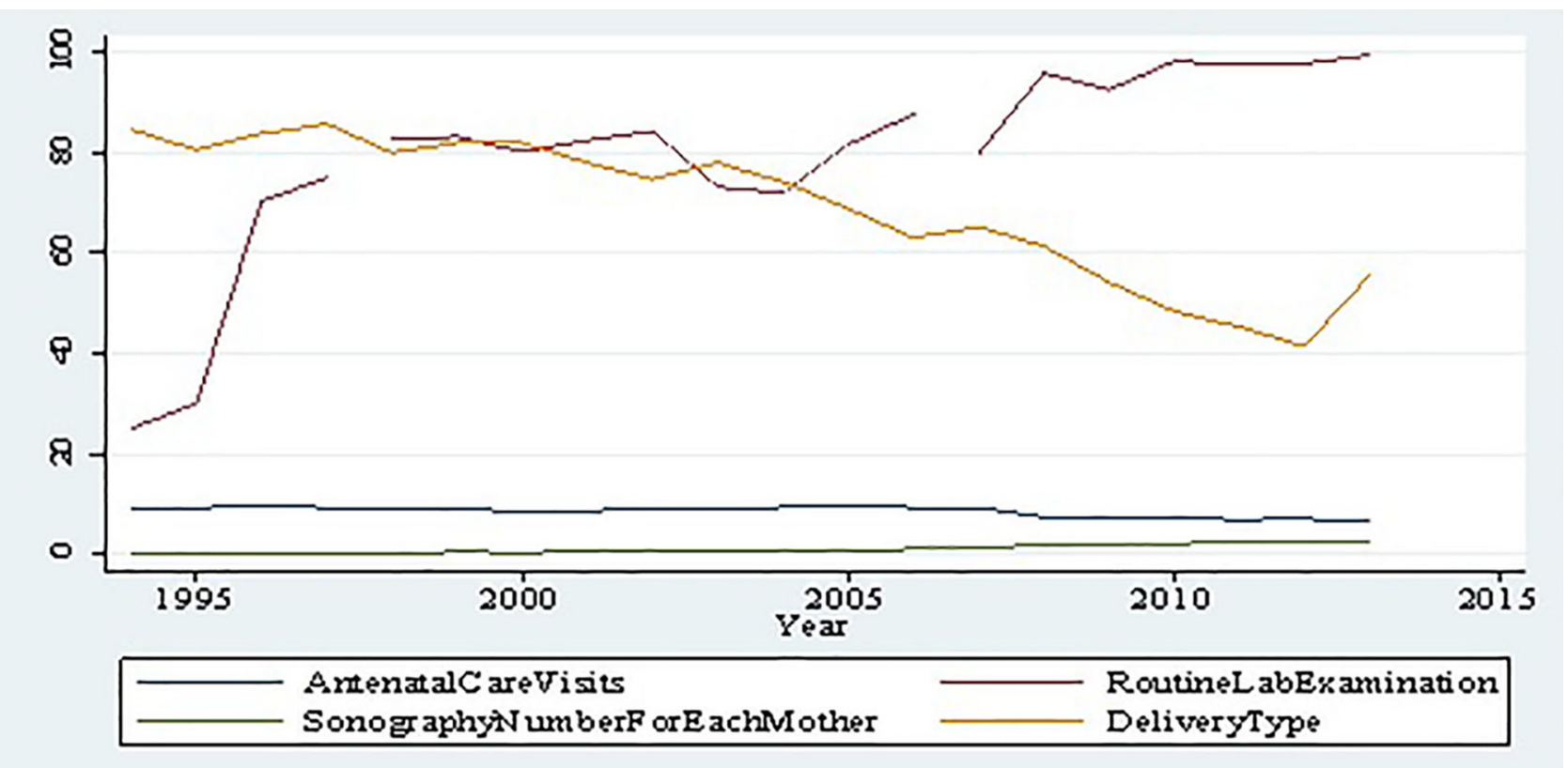

Figure 1 Trends of changes in process indicators (number of antenatal care visits, number of ultrasound, laboratory tests and proportion of normal vaginal delivery) from 1993 to 2013 in rural areas of East Azerbaijan province, Iran. Source: authors' interpretation of data from registered pregnant women in rural area of East Azerbaijan, Iran (1993-2013). 


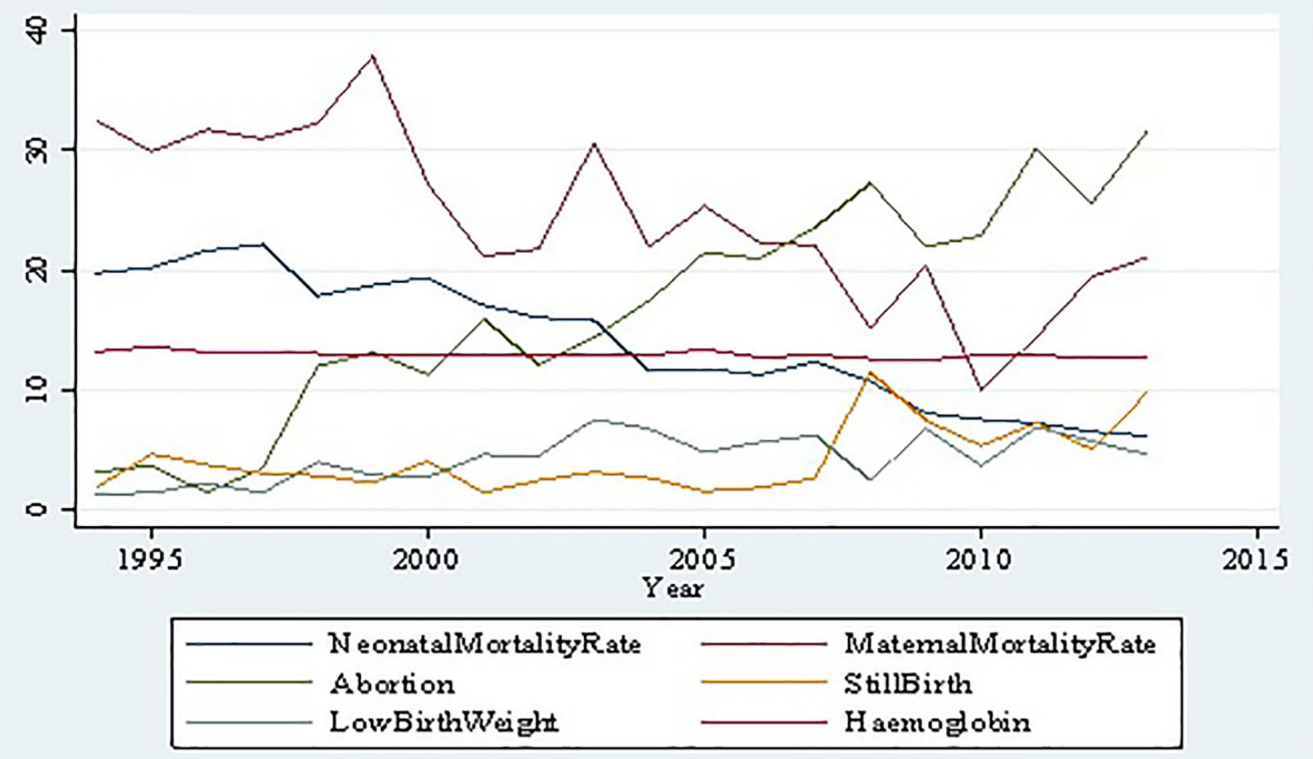

Figure 2 Trends of changes in neonatal and maternal health outcome indicators (neonatal mortality rate, maternal mortality rate, history of abortions and stillbirths, birth weight and first measured haemoglobin) over the study period (1993-2013) in rural areas of East Azerbaijan province, Iran. Source: authors' interpretation of data from registered pregnant women in rural area of East Azerbaijan, Iran (1993-2013).

are statistically different. If the 'time' coefficient is significant, it means that there were changes in the response indicator over the study time regardless of the intervention time. If the 'time-intervention interaction' is significant, it shows that the slope of changes in the response indicator trend before and after the intervention time is different.

\section{Process indicators}

Antenatal care visits

Over two decades covered by the study, the trend of ACVs had changed from a relatively stable trend to a sharp declining one. The independent impact of time and the programme on ACVs was not significant, but the interaction term (the slope of the decreasing trend) increased sharply after the intervention time both in unadjusted $(b=-0.36, \quad p<0.001)$ and adjusted models $(b=-0.36$, $\mathrm{p}<0.001)$.

\section{Routine laboratory tests and ultrasound}

The rate of routine laboratory tests, ultrasound and their repetitions during the pregnancy had increased over the years. There was a significant (in both unadjusted and adjusted models) independent association between time, the intervention and ultrasound (unadjusted $b=3.28$, $\mathrm{p}<0.001$ and adjusted $\mathrm{b}=2.40, \mathrm{p}=0.046$ for time; unadjusted $b=16.78, p=0.043$ and adjusted $b=19.31, p=0.049$ for intervention). Their interaction term did not have a significant association with these indicators. In contrast, repetition of ultrasound had significant association with interaction term (unadjusted $\mathrm{b}=0.21, \mathrm{p}<0.001$ and adjusted $\mathrm{b}=0.20, \mathrm{p}=0.008)$ and the unadjusted and adjusted independent effects of time $(b=3.28, p<0.001)$.
The independent impact of intervention on routine tests was not significant, but adjusted independent effect of time was significant $(b=7.70, p=0.015)$. The slope of trend of routine test did not vary before and after the intervention.

\section{Normal delivery}

The ratio of normal vaginal deliveries showed a decreasing trend during the study years (unadjusted $\mathrm{b}=-0.94, \mathrm{p}<0.001$; adjusted $\mathrm{b}=-0.81, \mathrm{p}=0.026)$, as well as before and after the intervention (unadjusted $\mathrm{b}=-7.41$, $p=0.008$; adjusted $b=-7.07, p=0.006$ ). After controlling for the structural confounders, the significant difference in the slope of normal deliveries trend that was observed for the unadjusted model before and after the intervention $(\mathrm{b}=-1.91, \mathrm{p}=0.035)$ disappeared in the adjusted model $(\mathrm{b}=1.33, \mathrm{p}=0.266)$.

\section{Outcome indicators}

\section{Mortality indicators}

According to the unadjusted model, NMR and MMR had declined over the study years $(b=-0.77, p=0.002$ and $\mathrm{b}=-0.95, \mathrm{p}=0.004)$. After adjustment of structural confounders, this association, however, was true only for NMR ( $b=-0.56, p=0.021)$, but not for MMR ( $b=0.69$, $\mathrm{p}=0.33$ ). The independent effect of FP programme and its interaction with time did not show any significant association with these two indicators. Moreover, there was a significant increasing trend for the history of abortion in both unadjusted $(b=1.54, p<0.001)$ and adjusted $(b=1.15$, $\mathrm{p}=0.009$ ) models, regardless of the intervention. However, only the adjusted effect of intervention on the history of abortion was significant $(b=4.28, p=0.047)$. No significant 

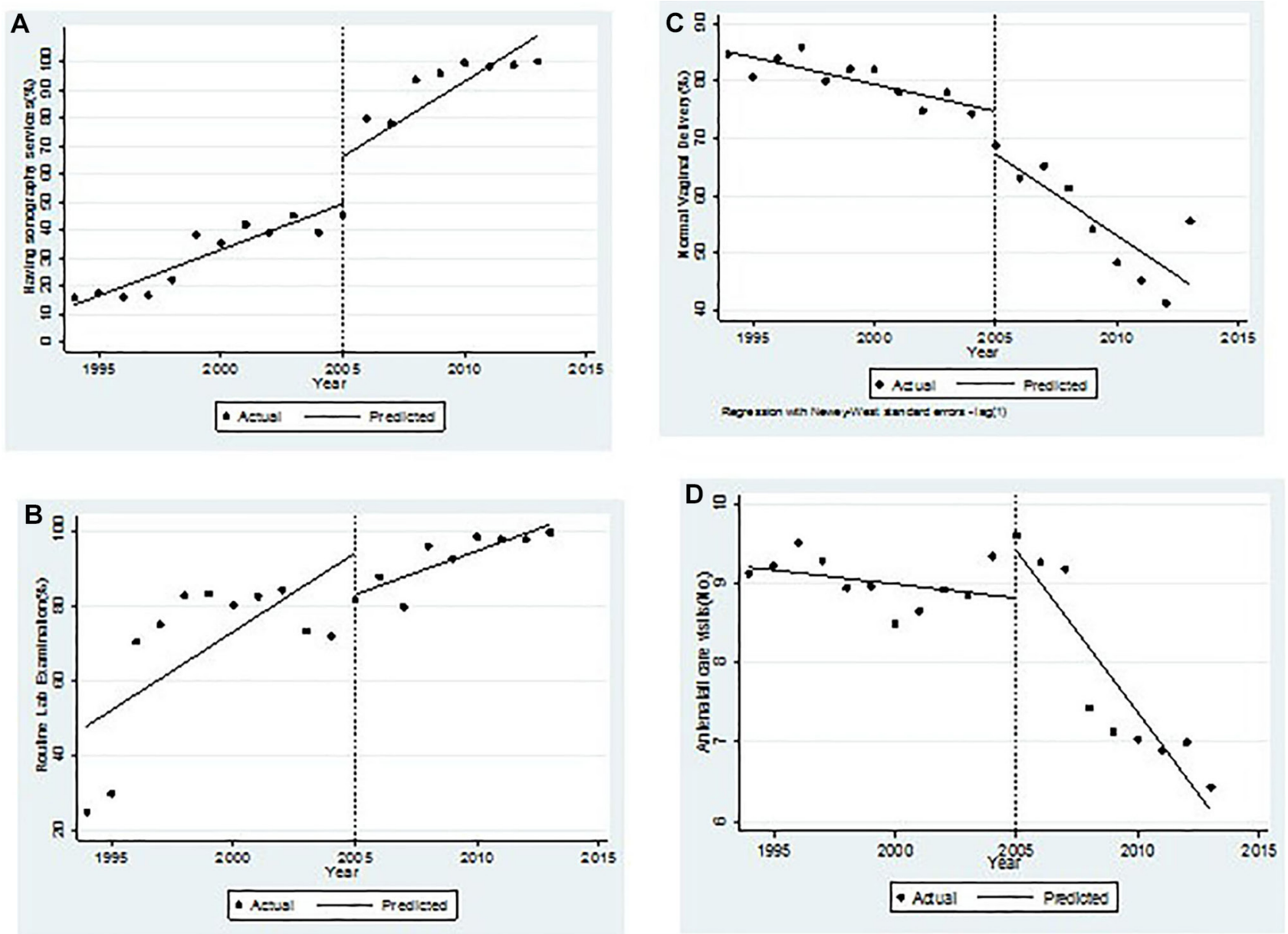

Figure 3 Scatter plot of the changes in trend of neonatal and maternal health process indicators in selected rural areas of East Azerbaijan province, Iran (1994-2013). Source: authors' interpretation of data from registered pregnant women in rural area of East Azerbaijan, Iran (1993-2013). The trends and intervention effects in process indicators point to an increasing trend in (A) ultrasound and (B) routine laboratory examinations but a decreasing trend in (C) natural vaginal delivery and (D) the number of antenatal care visits. The solid lines in the plots are the adjusted lines for the trend of values over the years.

slope change was observed for the history of abortion in both adjusted and unadjusted models. Finally, the independent effect of time and intervention on the history of stillbirths was not significant over the study years. Nonetheless, the slope of the history of stillbirths trend showed a significant variation before and after the intervention in both unadjusted $(\mathrm{b}=0.84, \mathrm{p}=0.006)$ and adjusted $(\mathrm{b}=1.72$, $\mathrm{p}<0.001)$ models.

\section{Other outcome indicators}

For outcome indicators other than mortality indicators, $\mathrm{BW}$ and first measured $\mathrm{Hb}$ were significant associated with effects of time and the interaction term in both adjusted and unadjusted models. The coefficient for the interaction term in adjusted analysis was $33.2(\mathrm{p}<0.001)$, showing of a dramatic change in the slop of the BW trend before and after the FP programme. The maternal $\mathrm{Hb}$ level showed a decreasing trend during the study years in the unadjusted model $(\mathrm{b}=-0.04, \mathrm{p}=0.007)$. There was no significant relation between $\mathrm{Hb}$ level and the intervention even after controlling for structural confounders.
The joint effect of time and the intervention was not associated with $\mathrm{Hb}$ values in both adjusted and unadjusted models.

\section{DISCUSSION}

Following the improvement of rural inhabitants' access to medical services, many studies predicted the improvement in $\mathrm{MCH}$ indicators as the main achievements of the FP plan in Iran. ${ }^{14}{ }^{35-37}$ These improvements were expected mainly due to proper involvement of physicians and midwives in the antenatal care. ${ }^{1435}{ }^{36}$ It should be considered that the reductions in NMR and MMR after the provision of maternal and child health services in the first health system reform (implementation of the PHC network in 1985) in Iran was partly due to a higher rate of maternal and neonatal mortality in those years (high baseline rates). Therefore, the recent reform (FP programme) that upgraded the PHC network in rural area also targeted previously unachieved and unrealised $\mathrm{MCH}$ goals. The FP programme enriched the $\mathrm{MCH}$ services 

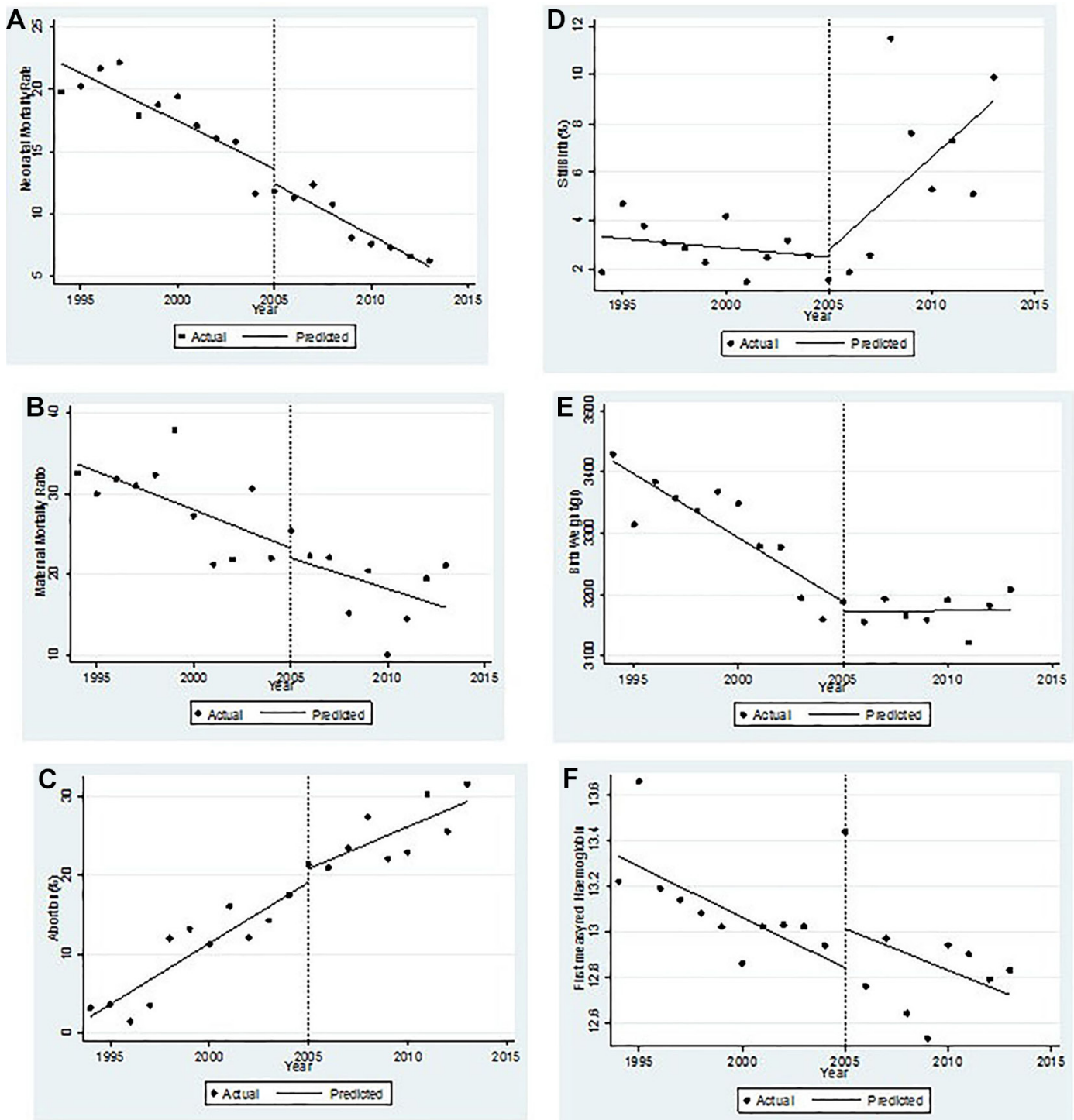

Figure 4 Scatter plot of the changes in the time trend of neonatal and maternal health process indicators in selected rural areas of East Azerbaijan province, Iran, 1994-2013. Source: authors' interpretation of data (add data source, years). Trends of (A) neonatal mortality rate, $(B)$ maternal mortality, $(C)$ abortion history ratio, (D) stillbirths history ratio, (E) birth weight and (F) the value of first haemoglobin $(\mathrm{Hb})$ in pregnancy are shown in the following graphs in figure 4 . As the graphs show, there was a constant trend for number of abortion and a soaring trend for stillbirths. Also, a descending trend without any dramatic slope change before and after the intervention was observed for neonatal mortality rate, maternal mortality ratio and the values of $\mathrm{Hb}$. Interestingly, there was a considerable slope change in birth weight trend. In fact, a decreasing trend of birth weights before the intervention turned to a constant trend after the intervention.

through provision of family healthcare services, ${ }^{18} 35$ improvement of services quality, ${ }^{36}{ }^{37}$ and promotion of perinatal care and safe delivery in rural areas. ${ }^{14}$

This study shows that the FP programme can promote process indicators, as well as proximal outcome indicators (ie, BW), better than the mortality indicators (MMR and NMR). There was even some increase in the ratio of mothers who have experienced stillbirths and to some extent NMR after the implementation of the programme in 2005. Although this increase is likely to originate partly from a better registration of a fetal death following the intervention, there should be other determinants of maternal and neonatal health that are different from sheer availability and affordability of health services that the FP programme secured.

The frequency of pregnancy ultrasound had increased over the years as well. This might be due to the free provision of these services after the programme implementation. These results are in line with other studies conducted in Cuba. ${ }^{13}$ At least one ultrasound session during gestation is recommended to diagnose abnormalities. ${ }^{38}$ However, easier access to physicians, along with less concern about financial bearings, had led to more use of healthcare services by pregnant women. ${ }^{26}{ }^{29}$ Our findings also showed reductions in the number of vaginal deliveries. In fact, the FP programme failed to stop the 
increasing trend of caesarean sections among the study population. It should be borne in mind that the FP intervention was also likely to increase caesarean sections through the provision of better diagnostic services and over-medicalisation of pregnant women. ${ }^{39}$ This is in line with another study that has reported similar findings. ${ }^{29}$

Maternal $\mathrm{Hb}$ level is supposed to be influenced by nutritional and supplementary nutritional services. As some improvements were expected in the provision of micronutrients supplementation for pregnant mothers following the increase in the access to health services, an increase in the normal range of $\mathrm{Hb}$ levels was expected. ${ }^{40}$ However, our study did not show such a result.

Interestingly, there was a critical change in the decreasing trend of $\mathrm{BW}$, indicating that service availability and affordability is a strong determinant of this indicator. This reduction is one of the main positive effects of the FP programme in Iran. ${ }^{41-44}$ Nonetheless, there is no universal agreement on indicators of FP success. Many studies have referred to indicators such as MMR, NMR, infant mortality rate, childbirth by skilled and trained personnel, caesarean delivery rate, abortion ratio, stillbirths ratio and BW. ${ }^{33}$ According to these studies, a better access to health services $^{6}$ can lead to a decrease in prenatal mortality, history of stillbirths and infant death rates during the first week delivery. ${ }^{41}{ }^{45}$ It can also increase the survival chance of low BW infants. ${ }^{41}{ }^{46}$ Although the reduction of MMR has been considered as a significant achievement of the FP reform by some studies, the programme did not have a significant effect on the decreasing trend of MMR in our study. It should be noted that any improvement in MMR trend is also highly dependent on social determinants of health. ${ }^{46}$ However, in countries with medium and low level of MMR, more targeted intervention should be considered. The findings of our study showed that the FP programme had no significant effect on NMR trend. This result differs from a previous study conducted in Iran. ${ }^{18}$ Another difference was also seen in the ratio of abortions, which increased after the programme in our study but was found to have a reducing trend in the previous studies. ${ }^{141}$ This difference can be partly explained by the differences in the methods of data collection. Previous studies were based on national and provincial statistics reports (aggregated data) and their time periods were shorter than the period in our study. They also did not adjust for possible confounders. ${ }^{1847}$

Our study used data for a relatively longer period of time, covering almost $100 \%$ of its target population. A random sampling approach was used to select the study samples from recorded registries over the years. These characteristics make the study result less prone to selection bias. However, the effect of time-varying confounders could not be ruled out completely. In fact, having no concurrent control group to discriminate the effect of FP from changes that would have happened without FP is a major limitation of the study. Although the urban population (with more than 200000 inhabitants) could have been considered as the comparison groups, the 
fundamental difference between these settings could produce a number of methodological challenges. Finally, as there is little difference between the features of the study sample and the characteristics of the representative sample reported in the latest national census in $2016,{ }^{48}$ demographic health survey in $2011^{49}$ and health system reports,$^{50}$ the findings of this study can be generalised, with some level of uncertainty, to rural areas of the entire country.

\section{CONCLUSION}

Our findings showed that introduction of the FP programme had a significant effect on process indicators and proximal outcome variables (ie, BW) in Iran. In addition, due to the accurate reporting and documentation of $\mathrm{MCH}$ records, the number of stillbirths and abortions significantly increased after the FP programme implementation. Interestingly, the effect of the reform on decreasing trends of MMR and NMR was not significant. It shows that along with some service availability factors that were addressed by the FP programme, there are some other effective factors that should be considered in order to improve the $\mathrm{MCH}$ indicators.

\section{Author affiliations}

${ }^{1}$ Department of Community Medicine, School of Medicine, Iranian Center of Excellence in Health Management, Tabriz University of Medical Sciences, Tabriz, Iran

${ }^{2}$ Health Services Management Research Center, Iranian Center of Excellence in Health Management, School of Management and Medical Informatics, Tabriz University of Medical Sciences, Tabriz, Iran

${ }^{3}$ Social Determinants of Health Research Center, Tabriz University of Medical Sciences, Tabriz, Iran

${ }^{4}$ Knowledge Utilization Research Center, Tehran University of Medical Sciences, Tehran, Iran

${ }^{5}$ Road Traffic Injury Research Center, Tabriz University of Medical Sciences, Tabriz, Iran

${ }^{6}$ Department of Statistics and Epidemiology, Faculty of Health, Tabriz University of Medical Sciences, Tabriz, Iran

${ }^{7}$ National Institute for Health Research Collaboration for Leadership in Applied Health Research and Care, North West Coast (NIHR CLAHRC NWC), Institute of Psychology, Health and Society, Health Services Research Department, University of Liverpool, Liverpool, UK

${ }^{8}$ Department of Infectious Disease Epidemiology, London School of Hygiene \& Tropical Medicine, London, UK

Acknowledgements We thank the staff working in health houses who helped us in data collection process. We also thank Jonathan Martin for constructive criticism of the manuscript.

Contributors LD and HJB designed the study. AA and MAJ conducted the statistical analysis. The manuscript was drafted by LD and HJB, with input from AA, MAJ, EKM and VSG. All authors reviewed and helped to revise the manuscript.

Funding The authors have not declared a specific grant for this research from any funding agency in the public, commercial or not-for-profit sectors. Esmaeil Khedmati Morasae is part-funded by the National Institute for Health Research Collaboration for Leadership in AppliedHealth Research and Care, North West Coast (NIHR CLAHRC NWC). The views expressed are those of the author and not necessary those of the NHS, NIHR or Department of Health.

Competing interests None declared.

Patient consent for publication Not required.
Ethics approval This study was approved by the ethics committee of Tabriz University of Medical Sciences, Tabriz, Iran (ethics approval code: IR.TBZMED. REC.2014.221).

Provenance and peer review Not commissioned; externally peer reviewed.

Data sharing statement Raw data are available on request.

Open access This is an open access article distributed in accordance with the Creative Commons Attribution Non Commercial (CC BY-NC 4.0) license, which permits others to distribute, remix, adapt, build upon this work non-commercially, and license their derivative works on different terms, provided the original work is properly cited, appropriate credit is given, any changes made indicated, and the use is non-commercial. See: http://creativecommons.org/licenses/by-nc/4.0/.

\section{REFERENCES}

1. Travis P, Bennett S, Haines A, et al. Overcoming health-systems constraints to achieve the Millennium Development Goals. Lancet 2004;364:900-6.

2. World Health Organization. Declaration of Alma-Ata. International Conference on Primary Health Care, Alma-Ata, USSR, 6-12 September 1978. 1978 http://www.who.int/publications/almaata declaration_en.pdf

3. Takian A, Doshmangir L, Rashidian A. Implementing family physician programme in rural Iran: exploring the role of an existing primary health care network. Fam Pract 2013;30:551-9.

4. Jabbari H, Pezeshki MZ, Naghavi-Behzad M, et al. Relationship between job satisfaction and performance of primary care physicians after the family physician reform of east Azerbaijan province in Northwest Iran. Indian J Public Health 2014;58:256.

5. Goudarzi S, Kameli ME, Hatami H. Improvement in health indicators of islamic republic of iran in the years 2004 and 2008. Iran Red Crescent Med J 2011;13:574.

6. Tabrizi JS, Pourasghar F, Gholamzadeh Nikjoo R. Status of Iran's Primary Health Care System in Terms of Health Systems Control Knobs: A Review Article. Iran J Public Health 2017;46:1156-66.

7. World Health Organization. The world health report 2008: primary health care now more than ever. 2008. Geneva: WHO, 2015.

8. Rashidian A, Joudaki H, Khodayari-Moez E, et al. The impact of rural health system reform on hospitalization rates in the Islamic Republic of Iran: an interrupted time series. Bull World Health Organ 2013:91:942-9.

9. Anon. Iranian health houses open the door to primary care. Bull World Health Organ 2008;86:585-6.

10. Takian A, Rashidian A, Kabir MJ. Expediency and coincidence in reengineering a health system: an interpretive approach to formation of family medicine in Iran. Health Policy Plan 2011;26:163-73.

11. Ministry of Health and Medical Education. Family physician program and rural health insurance plan. Iran Ministry of Health and Medical Education, 2016. Practical Guide.

12. Ekman B, Pathmanathan I, Liljestrand J. Integrating health interventions for women, newborn babies, and children: a framework for action. Lancet 2008;372:990-1000.

13. Jabbari H, Pezeshki MZ, Naghavi-Behzad M, et al. What is the relationship between family physicians' job satisfaction associated and their educational performance? Journal of Analytical Research in Clinical Medicine 2015;3:30-6.

14. Alizadeh M, Jabbari Birami H, Moradi S. Reproductive health of women in rural areas of East Azerbaijan-Iran, before and after implementation of rural Family Physician program: an ecologic study. J Caring Sci 2015;4:321-30.

15. Jafari F, Eftekhar H, Pourreza A, et al. Socio-economic and medical determinants of low birth weight in Iran: 20 years after establishment of a primary healthcare network. Public Health 2010;124:153-8.

16. Khayatzadeh-Mahani A, Takian A. Family physician program in Iran: considerations for adapting the policy in urban settings. Arch Iran Med 2014;17:776-8.

17. Esmaeili R, Hadian M, Rashidian A, et al. Family medicine in Iran: facing the health system challenges. Glob J Health Sci 2014;7:260-6.

18. Naderimagham $S$, Jamshidi $H$, Khajavi $A$, et al. Impact of rural family physician program on child mortality rates in Iran: a time-series study. Popul Health Metr 2017;15:21.

19. Javanparast $S$, Baum $F$, Labonte $R$, et al. A policy review of the community health worker programme in Iran. J Public Health Policy 2011;32:263-76.

20. Kalhor R, Azmal M, Kiaei MZ, et al. Situational analysis of human resources in family physician program: survey from iran. Mater Sociomed 2014;26:195-7. 
21. Azami-Aghdash S, Tabrizi J-S, Mohseni M, et al. Nine years of publications on strengths and weaknesses of Family Physician Program in rural area of Iran: a systematic review. J Anal Res Clin Med 2016;4:182-95.

22. Wiegers TA. General practitioners and their role in maternity care. Health Policy 2003;66:51-9.

23. Bernal JL, Cummins S, Gasparrini A. Interrupted time series regression for the evaluation of public health interventions: a tutorial. Int J Epidemiol 2017;46:348-55.

24. Miteniece E, Pavlova M, Rechel B, et al. Barriers to accessing adequate maternal care in Central and Eastern European countries: a systematic literature review. Soc Sci Med 2017;177:1-8.

25. Basinga P, Gertler PJ, Binagwaho A, et al. Effect on maternal and child health services in Rwanda of payment to primary healthcare providers for performance: an impact evaluation. The Lancet 2011;377:1421-8.

26. Macinko J, Guanais FC, de Fátima M, et al. Evaluation of the impact of the Family Health Program on infant mortality in Brazil, 1990-2002. $J$ Epidemiol Community Health 2006;60:13-19.

27. Atun R, de Andrade LO, Almeida G, et al. Health-system reform and universal health coverage in Latin America. Lancet 2015;385:1230-47.

28. Bucagu M, Kagubare JM, Basinga $P$, et al. Impact of health systems strengthening on coverage of maternal health services in Rwanda, 2000-2010: a systematic review. Reprod Health Matters 2012;20:50-61.

29. Victora CG, Aquino EML, do Carmo Leal M, et al. Maternal and child health in Brazil: progress and challenges. Lancet 2011;377:1863-76.

30. Lagomarsino G, Garabrant A, Adyas A, et al. Moving towards universal health coverage: health insurance reforms in nine developing countries in Africa and Asia. Lancet 2012;380:933-43.

31. Mousavi SM, Sadeghifar J. Universal health coverage in Iran. Lancet Glob Health 2016;4:e305-6.

32. Mukiapini S. Baseline measures of Primary Health Care Team functioning and overall Primary Health Care performance at Du Noon Community Health Centre: University of Cape Town, 2017.

33. Escuriet R, White J, Beeckman K, et al. Assessing the performance of maternity care in Europe: a critical exploration of tools and indicators. BMC Health Serv Res 2015;15:491.

34. Wang H, Bhutta ZA, Coates MM, et al. Global, regional, national, and selected subnational levels of stillbirths, neonatal, infant, and under-5 mortality, 1980-2015: a systematic analysis for the Global Burden of Disease Study 2015. The Lancet 2016;388:1725-74.

35. Craven B, Islam S. Ordinary least-squares regression: Sage Publications, 2011.
36. Jabbari BH, Gasemzade H, Bakhshian F, et al. Evaluation of Family Physician Program Based on Family Health Indices, 2012.

37. Jabbari $H$, Bakhshian $F$, Velayati $A$, et al. Effectiveness of presence of physician and midwife in quantity and quality of family planning services in health care centers. J Family Community Med 2014;21:1.

38. De Maeseneer J, Willems S, De Sutter A, et al. Primary health care as a strategy for achieving equitable care: a literature review commissioned by the Health Systems Knowledge Network, 2007.

39. Yazdizadeh B, Nedjat S, Mohammad K, et al. Cesarean section rate in Iran, multidimensional approaches for behavioral change of providers: a qualitative study. BMC Health Serv Res 2011;11:159.

40. Jabbari $\mathrm{H}$, Bakhshian $\mathrm{F}$, Asgari M, et al. Antenatal Micronutrient Supplementation Relationship with Children's Weight and Height from Birth up to the Age of 18 Months. Iran J Public Health 2013:42:626.

41. Alizadeh M, Jabbari BH, Moradi S. Analysis of trends in birth outcomes and fertility measurs in the rural population of East Azerbaijan province, Iran: 2001-2013, 2015.

42. Saltman R, Bankauskaite V, Vrangbaek K. Primary care in the driver's seat?: Organizational reform in European primary care: McGraw-Hill Education (UK), 2005.

43. Kringos DS, Boerma WG, Bourgueil Y, et al. The European primary care monitor: structure, process and outcome indicators. BMC Fam Pract 2010;11:81.

44. Masic I, Hadziahmetovic M, Donev D, et al. Public health aspects of the family medicine concepts in South eastern europe. Mater Sociomed 2014;26:277-86.

45. Vahdaninia M, Tavafian SS, Montazeri A. Correlates of low birth weight in term pregnancies: a retrospective study from Iran. BMC Pregnancy Childbirth 2008;8:12.

46. Alizadeh M, Dastgiri S, Taghavi S, et al. The relationship between social determinants of health and pregnancy outcomes: a retrospective cohort study in Tabriz. Journal of Clinical Research \& Governance 2014;3:152-7.

47. Mc Donagh M, Goodburn E. Maternal health and health sector reform: opportunities and challenges. Safe motherhood strategies: a review of the evidence 2001.

48. Statistical Centre of Iran. Iranian national census of population and housing. 2016. Available in http://irandataportal.syr.edu/census/ census-2016.

49. RashidianA, Khabiri R, Khodayari-Moez E, et al. Islamic Republic of Iran's Multiple Indicator Demographic and Healh Survey. Int J Prev Med 2014;5:632-42.

50. Distric Health Profile. Health data center. 2018. Available in: https:// eazphcp.tbzmed.ac.ir. 